\title{
CORRESPONDENCE
}

\section{Post Office inertia}

SIR - It is interesting that a scientific journal, and one as influential as Nature, should take up the question of the telecommunications monopoly "deregulation"' (Nature 26 March, p.279, 23 April, p.619). The importance of this matter is not generally appreciated, and your articles contain some very pertinent comments.

This issue transcends party politics; though no doubt the fate of the British

Telecommunications Bill will be influenced by the usual "state ownership versus free enterprise"' dogma. The fact is that a country possessing an efficient inexpensive telecommunications system operates with an advantage over one which possesses a relatively expensive inefficient one.

Implementation policy for a universal communications system is important; it would be hard to argue that a remote farmhouse in Cumberland should be without a telephone because resources have been diverted to the profitable business area. But the wealthproducing capacity of the nation mainly resides within manufacturing and service industries, whose ability to create that wealth is substantially affected by the availability of efficient communication services.

It appears that US deregulation policy, falteringly followed since 1968, has not resulted in "cream-skimming"' at the expense of services in remote areas. There is an extraordinary range of facilities available in that country which are unavailable here.

I have a list of 60 organizations in the United States offering a range of telephone and data communications equipment; there are probably many more. The number of companies in this country catering for this demand, excluding US subsidiaries, can be counted on the fingers of one hand. The reason is twofold; first, the demand for these devices here is small as yet. Second, the inertia of large bureaucracies encourages a safe policy and the purchase of very long-lasting equipment. The UK telecommunications industry has until very recently been asked to supply out of date equipment to the Post Office. The industry's concentration on the manufacture of this equipment left it in a weak position when tendering for the large international telecommunications contracts which have been placed during the last few years. They were awarded clscwhere.

CITECH, A.E. CAWKELL

Uxbridge, $M d d x, U K$

\section{Bovine units}

SIR - With reference to Dr John Damuth's letter "Population density and body size in mammels"' (Nature 23 April, p.699), it has been a general "rule-of-thumb" of the US cattle industry that the annual sustained "carrying capacity" of grazing land is approximately equal to one cow unit per section (square mile) per inch of annual rainfall, with one additional inch of rainfall, with one additional inch of rainfall being assumed for each 1,000 feet of altitude over 5,000 feet; and, a cow unit being defined as a "'mother-cow with calf to natural weaning, plus one bull for about each 30 mother-cows.'

Seattle, Washington, USA C.P. ANDERSON

\section{Look harder}

SIR - Andrew Brooks in his letter (Nature 7 May, p.7) raises a problem which is of wide relevance for the effective application of research and development effort. He is correct in believing that the lack of training in use of information results in much unintentional duplication or misdirection of research. It is particularly galling to us that the area of astronomy in which Mr Brooks presumably undertook his research is covered by the "computerized"' Physics Abstracts which forms part of the INSPEC database. This database covering physics, electrotechnology and computing is in common with other databases accessible worldwide through a variety of on-line services.

The major difficulty is to make potential users aware of the range of information services and to train them in their use. Inclusion of such training in all undergraduate courses would obviously be a solution, although time for this training is not casily found in heavily-loaded courses. We in INSPEC would be willing to cooperate with universities and colleges to supplement their own efforts at either the undergraduate or postgraduate level.

Peter Ci.aguf

INSPEC, Institution of Electrical Engineers, Hitchin, Herts, UK

SIR - We read with great interest Andrew Brooks' letter (Nature 7 May, p.7) concerning the problems of literature searching as part of the $\mathrm{PhD}$ research project. For some years we have been tackling this problem at Leicester Polytechnic, where user education is now particularly well-developed. A team of five Academic Librarians has been appointed to train all levels of students in the importance of information and in the techniques involved in its acquisition, storage and retrieval.

We are particularly aware of the daunting size of the task facing postgraduate students in science and technology, when searching the literature as part of their own research. With this in mind we offer courses specifically dealing with the problem at this level, tailored to each postgraduate's own research area.

By means of lectures, demonstrations, practical work and individual tutorials the researchers are introduced to the diverse range of published and unpublished sources in their subject field. The principles and techniques involved in both manual and computerized information searching are explained, and demonstrations are given to show the potentialities of accessing information via online bibliographic data-bases. The library offers computerized information retrieval facilities to all research students, many of whom find that a combination of manual and computerized searching provides the best solution. Guidance is also given in related areas such as thesis presentation, report writing techniques and coping with foreign language material.

Similar facilities are provided in several other academic institutions. More widespread encouragement of this trend would go a long way towards solving the problems outlined by Mr Brooks.

RUTH WEBB

The Library, Carolyn Hall.

Leicester Polytechnic, UK

\section{The fact is}

$\mathrm{SIR}$ - Disputes among the supporters of evolution are often only "a matter of presentation". For example, "Evolution is a fact" is a statement I thoroughly dislike, but is understandable to those who have traced the many meanings of "fact". The postulates of a well established theory are sometimes called facts. Mitchell ${ }^{1}$ gives the postulates of the chemiosmotic theory and then points out that they are now considered to be facts by most persons. So the postulate-fact confusion arises from the failure to specify one's temporal point of view and adherence to certain views.

The terms "true", "proof", "belief" and "falsification" are often carelessly used when discussing evolution. The first two terms are so final in their meaning that they have mostly disappeared from the discussions of the complex theories. Theories of very limited scope can often be proven true, but the broad, general theories never are. Since "belief" is a favourite term of the creationists and since for them it is something strong and final, scientists could well omit the term, as many have.

Only when one examines the structure of knowledge in evolution can one evaluate "falsification" used in its simple, literal sense. Evolution consists of a system of hundreds of theories ${ }^{2}$ which stem from Darwin's two major theories - the kinematic theory of descent with modification and the dynamic theory of natural selection. These theories in Darwinian and neo-Darwinian forms have spawned and are spawning hierarchies of subtheories. Some of the postulates of the major theories and subtheories and some of the the subtheories as a whole may be falsifiable, but usually only new postulates and new subtheories are falsified and discarded. The usual fate of established postulates and theories is not falsification but limitation. Decades ago Delbruck ${ }^{3}$ cautioned biologists about the folly of discarding good laws and theories on the grounds that they had limited ranges of applicability.

The testing of a major theory rests with the testing of its subtheories and the fate of the major theory is determined not by a single test, but by an evaluation of the successes and failures in its system of subtheories ${ }^{4-6}$.

"Falsification" is not then of much use in evaluating the major theories of evolution. The notion that evolution is not scientific as it is not falsifiable is based on a thin understanding of the structure of major theories, the way they develop and the part being tested.

Since creationists are planning the "ultimate court battle" in which they "will try to establish the 'religious' nature of evolutionary beliefs" ", it is essential that the scientific community clarify and solidify its views and terminology. We must find and state clearly our fundamental agreements so that our differences in presentation cannot be misconstrued and distorted.

RALPH W. LEWIS

Department of Natural Science, Michigan State University, USA

. Mitchell, P. Science 206, 1148-1159 (1979)

2. Lewis, R.W. Perspectives biol. Med. 23, 551-572 (1980).

3. Delbruck, M. Trans. Conn. Acad. Arts Sci. 38, 173 (1949).

4. Bunge, M. Appl. math. Modeling 2, 201-204 (1978).

. Caplan, A. Erkenntis 13, 261-278 (1978).

. Tuomi, J. \& Haukioja, E. Savonia 3, 1-8 (1979)

. Broad, W.J. Science 1331-1332 (1981). 